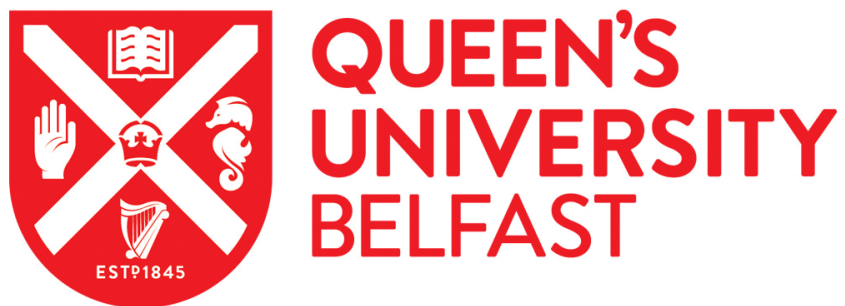

\section{Using choice experiments to explore the spatial distribution of willingness to pay for rural landscape improvements}

Campbell, D., Hutchinson, W. G., \& Scarpa, R. (2009). Using choice experiments to explore the spatial distribution of willingness to pay for rural landscape improvements. Environment and Planning A, 41(1), 97-111. https://doi.org/10.1068/a4038

Published in:

Environment and Planning $A$

Document Version:

Peer reviewed version

Queen's University Belfast - Research Portal:

Link to publication record in Queen's University Belfast Research Portal

Publisher rights

(C) 2009 The Authors.

This work is made available online in accordance with the publisher's policies. Please refer to any applicable terms of use of the publisher.

\section{General rights}

Copyright for the publications made accessible via the Queen's University Belfast Research Portal is retained by the author(s) and / or other copyright owners and it is a condition of accessing these publications that users recognise and abide by the legal requirements associated with these rights.

Take down policy

The Research Portal is Queen's institutional repository that provides access to Queen's research output. Every effort has been made to ensure that content in the Research Portal does not infringe any person's rights, or applicable UK laws. If you discover content in the Research Portal that you believe breaches copyright or violates any law, please contact openaccess@qub.ac.uk. 


\title{
Influence of prolonged hospitalization on overall bed occupancy: a five-year single-centre study
}

\author{
M.P. QUINN ${ }^{1}$, A.E. COURTNEY ${ }^{1}$, D.G. FOGARTY ${ }^{1}$, D. O'REILLY ${ }^{2}$, C. CARDWELL $^{2}$ and \\ P.T. MCNAMEE ${ }^{1}$ \\ From the ${ }^{1}$ Regional Nephrology Unit, Belfast City Hospital, and ${ }^{2}$ Department of Public Health and \\ Epidemiology, The Queen's University, Belfast, UK
}

Received 3 March 2007 and in revised form 9 May 2007

\section{Summary}

Background: Effective bed use is crucial to an efficient NHS. Current targets suggest a decrease in mean occupancy as the most appropriate method of improving overall efficiency. The elderly and those suffering from complex medical problems are thought to account for a high proportion of overall bed occupancy.

Aim: To assess the effect of prolonged hospital stay (>100 days) on overall bed occupancy in a modern teaching hospital.

Design: Retrospective analysis.

Methods: Analysis of all admission episodes $(n=117178)$ over a five-year period in a large teaching hospital in a single UK region, serving a population of approximately 200000 . A logistic regression multi-factorial model was used to assess the effect of demographic and diagnostic variables on duration of stay.

Results: A prolonged stay ( $>100$ days) was seen in 648 admission episodes (0.6\%). These accounted for $11 \%$ of the overall bed occupancy over the 5 -year period. Excluding all prolonged admission episodes from our analysis made no difference to the overall median length of stay.

Discussion: Prolonged hospitalizations have a significant impact on bed occupancy. Targeting these very long (>100 days) hospital stays may better improve overall efficiency, compared to targeting mean or median length of stay.

\section{Introduction}

The economic burden of providing a 'free' health service in the UK is increasingly under scrutiny, with the need for cost savings emphasized by the increasing budget deficits in many trusts, leading in some to compulsory redundancies.

In June 2006, the National Health Service (NHS) Institute for Innovation and Improvement ${ }^{1}$ published strategies with the aim of improving NHS efficiency and productivity. The authors devote chapter 7 to methods of reducing the variation in length of stay (LOS) and improving the discharge process. In accordance with the advice that providers should 'measure and continuously monitor length of stay', our hospital practice has changed to ensure that all patients are being given an 'expected date of discharge' as soon as possible after admission. This is consistent with Department of Health $(\mathrm{DOH})$ policy. $^{2}$

Additionally, the Healthcare Commission indicators in the acute hospital portfolio include a measure of efficiency of use of medical and surgical beds, with a calculation of percentage of bed-days (number of patients multiplied by the length of stay) that could be saved if the average length of stay was reduced for various groups of patients. As well as LOS, the new targets focus on admission rates, aiming to reduce emergency bed-day use by $5 \%$ from the 2003/2004 baseline by 2008. ${ }^{3}$ However, Ham and colleagues concluded in their analysis of hospital bed use in the NHS that the differences in

Address correspondence to Dr M.P. Quinn, Regional Nephrology Unit, Level 11, Belfast City Hospital, 51 Lisburn Road, Belfast BT97AB, UK. email: mquinn05@qub.ac.uk

(c) The Author 2007. Published by Oxford University Press on behalf of the Association of Physicians.

All rights reserved. For Permissions, please email: journals.permissions@oxfordjournals.org 
length of stay were more important than differences in admission rates in accounting for overall differences in bed-day use. ${ }^{4}$

We propose that those who are hospitalized for very prolonged periods represent a more significant and potentially modifiable problem, in that they account for a disproportionately large percentage of total bed occupancy. We carried out a retrospective review of all admissions to our hospital between 1 January 2001 and 31 December 2005, and assessed the relative contributions of short- and long-stay patients to overall occupancy rates. We also assessed the clinical risk factors relating to prolonged admission.

\section{Methods}

\section{Study population}

The Belfast City Hospital Trust $(\mathrm{BCH})$ is a modern 744-bed university teaching hospital providing acute local services and key regional specialties, including renal medicine and a comprehensive range of cancer services. It does not provide obstetric or acute trauma services, but has a facility for rehabilitation following fractures in the elderly population. The $\mathrm{BCH}$ does not provide long-term care for elderly patients, and labels each elderly care bed as acute, although it provides short periods of respite care for a small number of patients. During the 2004/2005 financial year, the hospital dealt with 24248 day cases, 47313 Accident \& Emergency (A\&E) attendances and 194729 outpatient appointments.

\section{Data acquisition}

We extracted all admissions data for the period 1 January 2001 to 31 December 2005 from the Patient Administration System. These basic data included hospital number, date of birth and age, postcode, gender, admission date, admission unit, mode of admission, diagnoses, date of discharge and mode of discharge. The diagnoses were coded with the International Classification of Diseases (ICD) 10 code, so each admission episode had a primary, a secondary, and up to five additional diagnoses. Only completed episodes were included in the analysis. Those patients who had a hospital number indicating an in-patient psychiatry event on the $\mathrm{BCH}$ site were excluded from the analysis, as were patients who attended A\&E but did not require admission, i.e. did not have an in-patient hospital number. The duration of admission was calculated by the interval between admission and discharge in complete days.
Using this database, the number of admissions per patient and the duration of individual and cumulative admission periods were calculated. No generally accepted criteria for 'prolonged stay' are available; The Audit Commission, in reviewing NHS bed management, ${ }^{5}$ used three groupings: 'up to 14 days'; '15-55 days'; and '56-500 days'. We felt the inclusion of a number of additional categories, especially for smaller durations of stay, would be useful in further categorizing the contribution of short stays to overall bed use. Admission stays were thus classified as: $<10$ days; $10-19$ days; 20-49 days; 50-99 days; and >100 days. For comparison between groups, we prospectively choose 100 days as a cut-off point indicating a truly prolonged stay in hospital. We felt that few clinical conditions could reasonably lead to such a period of time as an in-patient in an acute hospital. Stroke is often recognized as a condition requiring the most prolonged in-patient stay, but recent analyses suggest that even with this diagnosis, LOS $>100$ days is very unusual. ${ }^{4,6}$ We therefore felt confident that this cut-off point was appropriate, and representative of prolonged stay.

\section{Statistical analyses}

Descriptive analysis of the demographics, administrative and clinical variables of patients involved was done in relation to their categorical duration of stay in hospital. Numerical variables are reported as means (SD) or medians (IQR), as appropriate to their distribution. Categorical variables are presented as proportions of sample size. Comparisons of categorical variables between groups used the $\chi^{2}$ test.

To facilitate further analysis, we grouped specific ICD codes into defined grouping variables, and subsequently categorized admission episodes based on the presence or absence of these variables, as evidenced by their primary, secondary and subsidiary ICD diagnoses. The ten categories created were: heart disease; chronic lung disease; diabetes mellitus; vascular disease; malignancy; stroke; dementia; other neurological conditions; kidney disease; and any fracture. Combined with age and gender, these variables were introduced into a multivariable logistic regression model, with results presented as odds ratios $(95 \% \mathrm{Cls})$ and associated $p$ values. Logistic regression analyses used SPSS v. 14.0. An additional logistic regression analysis was also done using robust variance standard errors to adjust for any correlation of length of stay within individuals, ${ }^{5}$ as some individuals were admitted to hospital during the study period more than once, potentially compromising the assumption 
Table 1 Admission episodes by duration of stay

\begin{tabular}{|c|c|c|c|c|c|c|}
\hline $\begin{array}{l}\text { Number of days per } \\
\text { admission... }\end{array}$ & $<10$ & $10-19$ & $20-49$ & $50-99$ & $\geqslant 100$ & Total \\
\hline $\begin{array}{l}\text { Number }(\%) \text { of } \\
\text { admissions }\end{array}$ & $94747(81 \%)$ & $12447(10.6 \%)$ & $7305(6.2 \%)$ & $1768(1.5 \%)$ & $648(0.6 \%)$ & 116915 \\
\hline $\begin{array}{l}\text { Number }(\%) \text { of } \\
\text { occupied bed-days }\end{array}$ & $293241(32 \%)$ & $179376(20 \%)$ & 223352 (24\%) & $120770(13 \%)$ & $102473(11 \%)$ & 919212 \\
\hline $\begin{array}{l}\text { Equivalent bed-days } \\
\text { occupied per year }\end{array}$ & 161 & 98 & 122 & 66 & 56 & 503 \\
\hline Mean (SD) age (years) & $54.2(20.6)$ & $65.9(17.7)$ & $69.5(16.4)$ & $75.4(14.6)$ & $77.6(13.4)$ & \\
\hline \multicolumn{7}{|c|}{ Number (\%) with diagnosis of:* } \\
\hline Heart disease & 36877 (39\%) & $6024(48 \%)$ & 3477 (48\%) & $879(50 \%)$ & $327(50 \%)$ & $47584(41 \%)$ \\
\hline Lung disease & $13495(14 \%)$ & $2779(22 \%)$ & $1336(18 \%)$ & $288(16 \%)$ & 81 (13\%) & $17979(15 \%)$ \\
\hline Diabetes mellitus & $8864(9 \%)$ & 1877 (15\%) & $1174(16 \%)$ & $302(17 \%)$ & $83(13 \%)$ & $12300(11 \%)$ \\
\hline Vascular disease & 3879 (4\%) & $1260(10 \%)$ & $921(13 \%)$ & $236(13 \%)$ & $61(9 \%)$ & $6357(5 \%)$ \\
\hline Malignancy & 13837 (15\%) & $3232(26 \%)$ & $2326(32 \%)$ & $383(22 \%)$ & $79(12 \%)$ & $19857(17 \%)$ \\
\hline Stroke & 3961 (4\%) & $1189(10 \%)$ & $861(12 \%)$ & $349(20 \%)$ & $179(28 \%)$ & $6539(6 \%)$ \\
\hline Dementia & $1797(2 \%)$ & $523(4 \%)$ & $459(6 \%)$ & $202(11 \%)$ & $102(16 \%)$ & $3083(3 \%)$ \\
\hline $\begin{array}{l}\text { Other neurological } \\
\text { disease }\end{array}$ & $962(1 \%)$ & $273(2 \%)$ & $199(3 \%)$ & $66(4 \%)$ & $32(5 \%)$ & $1532(1 \%)$ \\
\hline Fracture & $951(1 \%)$ & $267(2 \%)$ & $324(4 \%)$ & $147(8 \%)$ & 58 (9\%) & $1747(1 \%)$ \\
\hline Kidney disease & $5362(6 \%)$ & 1507 (12\%) & 1079 (15\%) & 301 (17\%) & $88(14 \%)$ & 8337 (7\%) \\
\hline
\end{tabular}

* Many patients had more than one diagnosis.

of independence. This analysis used STATA, release 8.0 (Stata Corporation).

\section{Results}

During the 5-year period, there were 117178 admission episodes to the $\mathrm{BCH}$ site. After the exclusions outlined above, 116915 (99.8\%) admission episodes were available for further study; 70817 patients were admitted, and 35414 (50\%) were male.

The total number of bed-days was 919212 . The median (IQR) number of admission episodes was 1 (1), with $96 \%$ of patients having $<5$ admission episodes. Of the total number of admissions, 49420 $(42.2 \%)$ were single-admission episodes, and the median (IQR) stay in these single admission episodes was 2 (5) days. Those with multiple admission episodes were statistically more likely to stay longer: median stay 4 (8) days $(p<0.001$, Mann-Whitney $U$ test). The overall mean (SD) age of those admitted was 56.8 (20.6) years. There was a significant increase in the average age as length of hospitalization was prolonged, from 54.2 years for those staying $<10$ days to 77.6 years in those with prolonged stay of $>100$ days $(p<0.001)$.
Consistent with the short overall median LOS, the vast majority of admissions (94747/116915, 81\%) lasted $<10$ days. These admissions accounted for $32 \%$ of the total number of bed-days occupied. There was an incremental decrease in the number of admission episodes with increasing LOS (Table 1), but a disproportionate corresponding increase in percentage occupancy of bed-days. Those with multiple co-morbid conditions were more likely to stay longer in hospital (Table 1).

The results of the logistic regression analysis are shown in Table 2. As expected, increasing age was the major risk factor for very prolonged hospital stay. The adjusted OR was $17.52(p<0.001)$ in those aged $>85$ years compared with those aged $<55$ years, and there was an increase in risk across the age categories ( $p$ for trend $<0.001$ ) as outlined below. Women were at increased risk of very prolonged stay (adjusted OR 1.52, $p<0.001$ ) compared with men. The risk of a long-stay admission was significantly increased in patients with stroke (adjusted OR 3.17), kidney disease (adjusted OR 1.65), fracture (adjusted OR 2.4), dementia (adjusted OR 1.85) or degenerative neurological disease (adjusted OR 2.19). In contrast, after adjustment for age, gender, and other diagnoses, patients with heart disease, lung disease and 
Table 2 Analysis of predictors of prolonged hospital stay ( $>100$ days)

\begin{tabular}{|c|c|c|c|c|c|}
\hline \multirow[t]{2}{*}{ Predictors } & \multirow{2}{*}{$\begin{array}{l}\text { Total } \\
\text { admissions }\end{array}$} & \multirow{2}{*}{$\begin{array}{l}\text { Long-stay } \\
\text { admissions (\%) }\end{array}$} & \multirow[t]{2}{*}{$p^{\mathrm{a}}$} & \multicolumn{2}{|l|}{ Adjusted $^{b}$} \\
\hline & & & & OR $(95 \% \mathrm{Cl})$ & $p$ \\
\hline \multicolumn{6}{|l|}{ Gender } \\
\hline Male & 59482 & $236(0.4 \%)$ & $<0.001$ & 1.00 (Ref. Cat.) & $<0.001$ \\
\hline $\begin{array}{l}\text { Female } \\
\text { Age (years) }\end{array}$ & 57433 & $412(0.7 \%)$ & & $1.53(1.28-1.80)$ & \\
\hline$<55$ & 48526 & $43(0.1 \%)$ & $\begin{array}{l}<0.001 \\
\left(<0.001^{\mathrm{C}}\right)\end{array}$ & 1.00 (Ref. Cat.) & $\begin{array}{l}<0.001 \\
\left(<0.001^{\mathrm{C}}\right)\end{array}$ \\
\hline $55-64$ & 19206 & $31(0.2 \%)$ & & $2.09(1.31-3.35)$ & \\
\hline $65-74$ & 21757 & $120(0.5 \%)$ & & $5.99(4.15-8.66)$ & \\
\hline $75-85$ & 19555 & $260(1.3 \%)$ & & $11.74(8.31-16.57)$ & \\
\hline$>85$ & 7677 & $194(2.5 \%)$ & & $17.52(12.27-25.01)$ & \\
\hline \multicolumn{6}{|c|}{ Heart disease } \\
\hline $\mathrm{N}$ & 69331 & $321(0.5 \%)$ & $<0.001$ & 1.00 (Ref. Cat.) & 0.006 \\
\hline Y & 47584 & $327(0.7 \%)$ & & $0.79(0.66-0.93)$ & \\
\hline \multicolumn{6}{|c|}{ Lung disease } \\
\hline $\mathrm{N}$ & 98936 & $567(0.6 \%)$ & 0.24 & 1.00 (Ref. Cat.) & $<0.001$ \\
\hline Y & 17979 & $81(0.5 \%)$ & & $0.64(0.50-0.82)$ & \\
\hline \multicolumn{6}{|c|}{ Diabetes mellitus } \\
\hline $\mathrm{N}$ & 104615 & $565(0.5 \%)$ & 0.33 & 1.00 (Ref. Cat.) & 0.360 \\
\hline Y & 12300 & $83(0.7 \%)$ & & $0.89(0.70-1.11)$ & \\
\hline \multicolumn{6}{|c|}{ Vascular disease } \\
\hline $\mathrm{N}$ & 110558 & $587(0.5 \%)$ & $<0.001$ & 1.00 (Ref. Cat.) & 0.282 \\
\hline Y & 6357 & $61(1.0 \%)$ & & $1.17(0.88-1.55)$ & \\
\hline \multicolumn{6}{|l|}{ Malignancy } \\
\hline $\mathrm{N}$ & 97058 & $569(0.6 \%)$ & 0.001 & 1.00 (Ref. Cat.) & 0.002 \\
\hline \multicolumn{6}{|l|}{ Stroke } \\
\hline $\mathrm{N}$ & 110376 & $468(0.4 \%)$ & $<0.001$ & 1.00 (Ref. Cat.) & $<0.001$ \\
\hline \multicolumn{6}{|l|}{ Dementia } \\
\hline $\mathrm{N}$ & 113832 & $546(0.5 \%)$ & $<0.001$ & 1.00 (Ref. Cat.) & $<0.001$ \\
\hline Y & 3083 & $102(3.3 \%)$ & & $1.85(1.45-2.35)$ & \\
\hline \multicolumn{6}{|c|}{ Other neurological disease } \\
\hline $\mathrm{N}$ & 115383 & $616(0.5 \%)$ & $<0.001$ & 1.00 (Ref. Cat.) & $<0.001$ \\
\hline $\begin{array}{l}\text { Y } \\
\text { Fracture }\end{array}$ & 1532 & $32(2.1 \%)$ & & $2.19(1.51-3.18)$ & \\
\hline $\mathrm{N}$ & 115168 & $590(0.5 \%)$ & $<0.001$ & 1.00 (Ref. Cat.) & $<0.001$ \\
\hline $\begin{array}{l}\text { Y } \\
\text { Kidney dise }\end{array}$ & 1747 & $58(3.3 \%)$ & & $2.40(1.78-3.32)$ & \\
\hline $\mathrm{N}$ & 108578 & $560(0.5 \%)$ & $<0.001$ & 1.00 (Ref. Cat.) & $<0.001$ \\
\hline Y & 8337 & $88(1.1 \%)$ & & $1.65(1.30-2.09)$ & \\
\hline
\end{tabular}

${ }^{\mathrm{a} B a s e d}$ upon $\chi^{2}$ test. ${ }^{\mathrm{b}}$ Model contains gender, age category, heart disease, lung disease, diabetes mellitus, vascular disease, malignancy, stroke, dementia, other neurological disease, fracture, and kidney disease. ${ }^{\mathrm{C}}$ Based upon test for linear trend across categories. 
malignancy were significantly less likely to stay for $>100$ days. The results of an additional logistic regression model adjusting for multiple visits per person (using robust variance standard errors) provided comparable results to those shown in Table 2, and therefore have not been presented.

\section{Discussion}

Bed occupancy, and its associated problems, is an emotive subject in the NHS. The aim to provide allcomers with appropriate timely treatment is the bedrock of the NHS. Year-round increased bed occupancy rates leave little redundancy in the system to cope with temporary increases in admission rates. The response has been to streamline systems to improve the throughput of patients, decreasing the time from admission to discharge. This attempt to decrease median length of stay in hospital is a laudable goal, but fails to recognize the potential benefits of targeting resources at those who spend a prolonged period of time in hospital. The central question is: do patients really require an acute in-patient bed for $>100$ days? Or does this simply reflect the lack of alternative, more appropriate care facilities, such as cottage hospitals and nursing homes, in our community? It seems extraordinary that $0.6 \%$ of admission episodes can account for over $10 \%$ of total bed occupancy over a 5 -year period.

This study demonstrates some of the inherent problems in seeking to optimize bed use by targeting mean lengths of stay. Concentrating effort and resources at those staying for shorter periods is unlikely to be as effective as targeting patients who stay for prolonged periods. Considering a simplified example from our data: if all patients with prolonged hospital stays of $>100$ days were excluded from our analysis, mean LOS would be unaltered, but bed occupancy would have been reduced by $>10 \%$. Identifying those with prolonged admissions and targeting resources to facilitate their discharge to a more appropriate establishment will have a much greater impact on bed occupancy than reducing the average hospital stay for patients admitted on certain days of the week, or admitted with a myocardial infarction, both of which are current performance targets in efficiency laid down by The Healthcare Commission. ${ }^{3}$

The Department of Health has recently published guidelines to help trusts to develop pathways and processes to improve the timely discharge of patients: ${ }^{2}$ a long and complex document beyond the remit of this discussion. However the guidelines and indeed much of the literature surrounding the subject are based on the assumption that there is an inherent problem with the system. These guidelines fail to recognize that a large proportion of the problem is not only system-related but subject-related. The characteristics of patients being admitted to acute hospitals continue to reflect the changes in population demographics in our communities. Our study has shown, like many before it, the ongoing association between age and prolonged hospital stay. ${ }^{8,9}$ As a population, we are living longer and are developing multiple, complex diseases requiring prolonged and complicated management. This is clearly reflected in our data (Table 1) as patients with accumulating diagnoses of chronic debilitating conditions stayed significantly longer in hospital.

\section{Weaknesses}

This study has limitations. Firstly, it does not allow us to comment on whether the discharge in individual admission episodes were appropriate or delayed, nor can we ascertain whether the discharge was delayed for reasons other than medical status. However, experientially it is seldom, if ever, that a hospitalization for acute medical issues is required for a period $>100$ days. Our data support this, as even in the diagnostic categories with the longest stays (dementia and fracture) only $3.3 \%$ of patients stayed $>100$ days; the vast majority were discharged earlier (Table 2). In practice, rehabilitation and social concerns following a significant illness are usually the reasons for prolonged hospitalization. Lack of continuity between hospital and community care has often been implicated as a cause of prolonged bed stays, ${ }^{9,10}$ and it may be that target setting in this area would be more useful in increasing NHS efficiency. Further work is required to determine the factors that necessitate hospitalization for $>100$ days, and we suggest that a prospective study would be appropriate and essential to identify where resources may best be used in this area. If anything, our report is likely to underestimate the impact of prolonged hospital stays, as by excluding incomplete admission episodes, we will have missed individuals who began an in-patient stay before January 2001 or who completed an in-patient stay after December 2005, but who stayed for $>100$ days.

\section{Conclusions}

Improving efficiency and productivity within the NHS is an important goal. Much recent policy is directed at reducing hospital length of stay and acute admissions in an effort to optimize the use of beds. Current performance targets, however, do not focus on those patients with prolonged admission 
episodes. This study examines the overall duration of stay within a large teaching hospital and challenges the current $\mathrm{DOH}$ policy, by suggesting that targeting patients who stay for prolonged periods, and effecting a more timely discharge, could be a much more effective and efficient use of resources.

\section{Acknowledgements}

We would like to thank Ms Denise Lynd, Information Department, Belfast City Hospital for her assistance with retrieval of LOS data.

\section{References}

1. The National Health Service (NHS) Institute for Innovation and Improvement, Productivity and Efficiency, June 2006. [http://www.institute.nhs.uk/products/productivityand efficiency.htm]

2. Department of Health (DOH). Discharge from hospital: pathway, process and practice; 2003. [http://www.doh. gov.uk/jointunit]

3. The Healthcare Commission. [http://www.healthcare commission.org.uk/homepage.cfm]
4. Ham C, York N, Sutch S, Shaw R. Hospital bed utilisation in the NHS, Kaiser Permanente, and the US Medicare programme: analysis of routine data. Br Med J 2003; Nov 29; 327: 1257.

5. Kirkwood BR, Sterne JAC. Essential Medical Statistics, 2nd edn. Oxford, Blackwell Science, 2003.

6. Audit Commission. Bed Management, Review of National Findings, 2003. [http://www.audit-commission.gov.uk]

7. Gagnon D, Nadeau S, Tam V. Ideal timing to transfer from an acute care hospital to an interdisciplinary inpatient rehabilitation program following a stroke: an exploratory study. BMC Health Serv Res 2006; 6:151.

8. Lang PO, Heitz D, Hedelin G, et al. Early markers of prolonged hospital stays in older people: a prospective, multicenter study of 908 inpatients in French acute hospitals. J Am Geriatr Soc 2006; 54:1031-9.

9. Victor CR, Healy J, Thomas A, Seargeant J. Older patients and delayed discharge from hospital. Health Soc Care Community 2000; 8:443-52.

10. Ellis A, Trappes-Lomax T, Fox M, Taylor R, Power M, Stead J, et al. Buying time II: an economic evaluation of a joint NHS/Social Services residential rehabilitation unit for older people on discharge from hospital. Health Soc Care Community 2006; 14:95-106. 